\title{
Comparative vector competence of North American Lyme disease vectors
}

\author{
Lisa I. Couper ${ }^{1}$, Youyun Yang ${ }^{2}$, Xiaofeng Frank Yang ${ }^{2}$ and Andrea Swei ${ }^{3^{*}}$ (i)
}

\begin{abstract}
Background: Understanding the drivers of Lyme disease incidence at broad spatial scales is critical for predicting and mitigating human disease risk. Previous studies have identified vector phenology and behavior, host community composition, and landscape features as drivers of variable Lyme disease risk. However, while the Lyme disease transmission cycles in the eastern and western USA involve different vector species (Ixodes scapularis and Ixodes pacificus, respectively), the role of vector-specific differences in transmission efficiency has not been directly examined. By comparing the performance of traits involved in vector competence between these two species, this study aims to identify how vector competence contributes to variable Lyme disease risk.
\end{abstract}

Methods: We used a suite of laboratory experiments to compare the performance of traits related to vector competence for the two USA Lyme disease vectors. For each species, we measured the rate of attachment to a common rodent host, the engorgement weight, and the efficiency of pathogen acquisition (host to tick) and pathogen transmission (tick to host) from laboratory mice. In measuring pathogen acquisition and transmission, we used two different pathogen strains, one sympatric with I. scapularis and one sympatric with I. pacificus, to assess the importance of vector-pathogen coevolutionary history in transmission dynamics.

Results: We found I. pacificus had significantly higher host attachment success and engorgement weights, but significantly lower pathogen transmission efficiency relative to I. scapularis. Molting success and pathogen acquisition did not differ between these two species. However, pathogen acquisition efficiency was significantly higher for both sympatric vector and pathogen strains than the allopatric pairings.

Conclusions: This study identified species-specific vector traits as a potential driver of broad scale variation in Lyme disease risk in the USA. In particular, the exceedingly low rates of pathogen transmission from tick to host observed for I. pacificus may limit Lyme disease transmission efficiency in the western USA. Further, observed variation in pathogen acquisition between sympatric and allopatric vector-pathogen strains indicate that vector-pathogen coevolutionary history may play a key role in transmission dynamics. These findings underscore the need to consider vector traits and vector-pathogen coevolution as important factors governing regional Lyme disease risk.

Keywords: Lyme disease, Ixodes scapularis, Ixodes pacificus, Vector competence, Pathogen acquisition, Pathogen transmission

\section{Background}

Tick-borne diseases pose serious threats to public health in the USA as many diseases are increasing in incidence

*Correspondence: aswei@sfsu.edu

${ }^{3}$ Department of Biology, San Francisco State University, San Francisco, CA, USA

Full list of author information is available at the end of the article and geographical distribution, new pathogens are emerging, and new vector species are introduced $[1,2]$. Despite efforts to manage tick populations and pathogen transmission, the most effective method for preventing human disease still relies on tick avoidance and prompt removal [3], necessitating a strong understanding of the spatial and temporal patterns of disease risk. Efforts to 
understand and predict spatial trends in tick-borne disease typically focus on regional disease systems as ticks are highly sensitive to local microhabitat conditions and host communities [4-8]. However, substantial spatial heterogeneity in human incidence exists at broad spatial scales. For example, reported cases of Lyme disease, the most common vector-borne disease in the USA, are scattered throughout the continental USA, but approximately $93 \%$ of cases occur in ten states in the Northeast and upper Midwest [9]. Despite the high spatial clustering of cases in these regions, the tick species responsible for vectoring Lyme disease are present in nearly half of all USA counties [10]. Identifying the factors underlying incidence across space, rather than vector presence alone, is thus critical for improved prediction and mitigation of human disease risk.

The divergent Lyme disease cycles in the eastern and western USA present an ideal system for studying ecological drivers of human incidence at broad spatial scales. While Lyme disease is endemic in both regions, the pathogen, Borrelia burgdorferi (sensu stricto), is maintained by different vector species in distinct enzootic cycles comprised of different reservoir hosts $[11,12]$. In the eastern USA, B. burgdorferi transmission is maintained by a suite of small mammal hosts, most notably white-footed mice, least chipmunks, long-tailed and short-tailed shrews and bushy-tailed squirrels; and transmitted between hosts by the blacklegged tick, Ixodes scapularis [13]. In the western USA, B. burgdorferi is maintained primarily by the western gray squirrel, dusky-footed woodrat and deer mice, and vectored by the western blacklegged tick, Ixodes pacificus [14].

While both of these systems feature small mammal pathogen reservoirs and ixodid tick vectors, Lyme disease incidence in the eastern and western USA differs by orders of magnitude [15]. Prior reports suggest that ecological drivers of broad-scale differences in incidence include variation in tick host community composition $[16,17]$, vector phenology $[18,19]$ and differences in vector questing behavior $[20,21]$. These factors may contribute to differences in incidence between the eastern and western USA, however, more fundamental differences in the competence of the two vector species involved, $I$. scapularis and I. pacificus, remain to be explored.

Prior comparisons of I. scapularis and I. pacificus indicate these species are genetically and morphologically similar [22, 23], have similar feeding and reproductive strategies [24], and similar host preferences in the laboratory [22]. Despite these similarities, these species exhibit key differences in their life histories, likely driven by the differing evolutionary and ecological conditions of their disjoint distributions. The distribution of $I$. scapularis extends across the eastern USA, with recent geographical expansions observed in the northeastern, northcentral and midwestern USA, while the distribution of $I$. pacificus covers the far western USA and has remained relatively stable in recent decades [10]. Thus, the host communities and climatic conditions experienced by each species differ markedly, generating differences in their host usage [25-27], phenology [24] and climate sensitivities [28]. The impact of these life history differences on vector traits related to competence is largely unexplored but may help further explain broad scale geographical differences in Lyme disease incidence.

Vector competence, the ability of a vector to acquire, maintain, and transmit pathogens underlies the efficiency of pathogen transmission [12, 29, 30]. Establishing vector competence for a particular tick species and pathogen requires successful execution of a sequence of steps [30] (Fig. 1, Table 1). Namely, a tick must find and attach to a competent host, acquire the pathogen during feeding, molt and maintain the pathogen during molting, then attach and transmit the pathogen to another host [31]. Given the number of steps involved, many vector-specific traits and extrinsic factors influence vector competence, enabling large variation in competence even in closely related species [32, 33]. However, comparisons of vector competence between species typically focus on one or two of the above steps [22, 34-36], obscuring the overall impact of vector competence on disease risk and hindering our ability to identify bottlenecks in transmission [37].

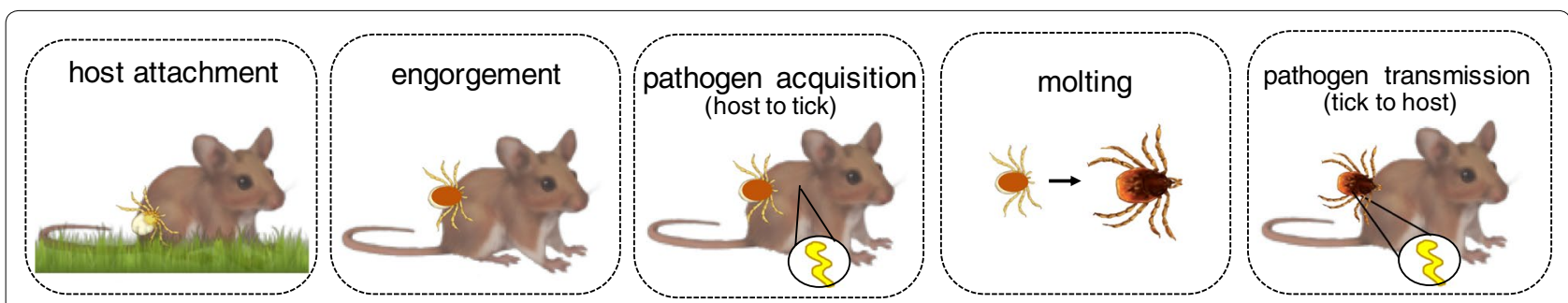

Fig. 1 Vector traits involved in vector competence. The panels depict, in order, an unengorged larva (I. scapularis or I. pacificus) seeking a rodent host, an engorged larva on a rodent host, an engorged larva transmitting B. burgdorferi to a rodent host, an engorged larva molting to the nymphal life stage, and a nymph transmitting $B$. burgdorferi to a rodent host. Tick and mouse graphics illustrated by Mona Luo 
Table 1 Vector competence traits measured in I. scapularis and I. pacificus

\begin{tabular}{|c|c|c|}
\hline Trait & Ecological significance & Result \\
\hline Host attachment success & $\begin{array}{l}\text { Successful attachment to a competent host, typically } \\
\text { a small mammal, is necessary for potential pathogen } \\
\text { acquisition [110] }\end{array}$ & $\begin{array}{l}\text { I. pacificus had significantly higher host attachment } \\
\text { success than I. scapularis }\end{array}$ \\
\hline Feeding rate & $\begin{array}{l}\text { Longer attachment to hosts can facilitate pathogen } \\
\text { transmission, but may also stimulate host immune } \\
\text { responses [111-113] }\end{array}$ & $\begin{array}{l}\text { I. scapularis fed to repletion significantly faster than I. } \\
\text { pacificus }\end{array}$ \\
\hline Engorgement weight & $\begin{array}{l}\text { Higher engorgement weights may reflect higher } \\
\text { resource uptake and be associated with greater molt- } \\
\text { ing success and/or survivorship [76] but see [59] }\end{array}$ & $\begin{array}{l}\text { I. pacificus had significantly higher engorgement } \\
\text { weights than I. scapularis }\end{array}$ \\
\hline Molting success & $\begin{array}{l}\text { Successful larval molting is a prerequisite for pathogen } \\
\text { transmission during the nymphal life stage [110]. } \\
\text { Transstadial transmission is also required but has } \\
\text { previously been measured at high rates for both } / \text {. } \\
\text { scapularis }[114,115]\end{array}$ & $\begin{array}{l}\text { An equal proportion of I. scapularis and I. pacificus suc- } \\
\text { cessfully molted }\end{array}$ \\
\hline Pathogen acquisition (host to tick) & $\begin{array}{l}\text { As } B \text {. burgdorferi is not vertically transmitted, pathogen } \\
\text { acquisition by larvae is crucial for B. burgdorferi main- } \\
\text { tenance and amplification [12] }\end{array}$ & $\begin{array}{l}\text { An equal proportion of I. scapularis and I. pacificus } \\
\text { acquired their respective sympatric pathogen strain, } \\
\text { and an equal but lower proportion of I. scapularis and } \\
\text { I. pacificus acquired their allopatric pathogen strain }\end{array}$ \\
\hline Pathogen transmission (tick to host) & $\begin{array}{l}\text { As the adult vector life stages typically feed on non- } \\
\text { competent reservoir hosts, efficient pathogen trans- } \\
\text { mission by nymphs to hosts is critical for B. burgdorferi } \\
\text { maintenance and amplification [12] }\end{array}$ & $\begin{array}{l}\text { 1. scapularis transmitted the pathogen to a greater } \\
\text { number of hosts than I. pacificus which did not } \\
\text { transmit to any hosts, although unequal numbers of } \\
\text { infected ticks were applied to hosts }\end{array}$ \\
\hline
\end{tabular}

To investigate the role of vector competence in Lyme disease transmission at broad spatial scales, we compared the performance of the two USA vector species, I. scapularis and I. pacificus, in various ecological and physiological processes involved in pathogen dynamics. Using controlled laboratory manipulations, we measured the host attachment and feeding rate, engorgement weight, larval molting success, and efficiency of pathogen acquisition (tick to host) and pathogen transmission (host to tick) (Fig. 1).

\section{Methods}

\section{Sample collection}

Larval I. scapularis and I. pacificus used for vector competence comparisons were obtained from BEI Resources (BEI Resources, Manassas, VA, USA; NR-44115, NR-44387). Colonies of I. scapularis and I. pacificus originated from ticks collected from vegetation in Rhode Island in 2003, and California in 2000, respectively. Both species were then reared under identical, standard lab conditions, entailing maintenance in sterile polystyrene containers in environmental incubators at a relative humidity of $90 \%$, temperature of $22 \pm 1{ }^{\circ} \mathrm{C}$, and a $16: 8 \mathrm{~h}$ light:dark photoperiod [38, 39]. Deer mice, Peromyscus maniculatus, were used for all host feeding assessments as this species is a common tick host found in the ranges of both I. scapularis and I. pacificus [39, 40]. Relative feeding on P. maniculatus is generally lower for $I$. pacificus relative to I. scapularis $[27,41,42]$ but in some regions such as the Midwest, the absolute mean burdens are similar $[43,44]$. Further, I. pacificus will readily parasitize $P$. maniculatus when available [41-43] and the lower natural parasitism rates are likely due to a preference for lizards rather than physiological incompetence for mice-feeding [43]. Adult female P. maniculatus bardii were obtained from the Peromyscus Genetic Stock Center at the University of South Carolina and were identical in age, sex and prior husbandry. Statistical comparisons of vector competence measurements were assessed via two-proportion Z-tests or Kruskal-Wallis tests, conducted in $\mathrm{R}$ v3.4.3.

\section{Host attachment and feeding rate}

The host attachment success of I. scapularis and I. pacificus was measured through laboratory feeding on $P$. maniculatus. Larval I. scapularis and I. pacificus were manually placed on naïve $P$. maniculatus that had been anesthetized with isoflurane. Two $P$. maniculatus were used for each tick species and 150 larvae were used per mouse for a total of 300 larvae of each tick species. After the initial placement of ticks on the mouse ears and neck, each mouse was held within a cloth bag for $16 \mathrm{~h}$ to provide increased opportunity for tick attachment [44]. After $16 \mathrm{~h}$, mice were removed from the bag and maintained in a wire cage held above a water dish into which ticks dropped off and were collected daily. Replete ticks were transferred to sterile polystyrene containers as described above. During these procedures, room temperature was 
maintained at $22 \pm 1{ }^{\circ} \mathrm{C}$, and a $16: 8 \mathrm{~h}$ light:dark photoperiod was used [39].

\section{Engorgement weight}

The weights of successfully fed larval $I$. scapularis and $I$. pacificus were measured using a Mettler Toledo analytical balance (Mettler Toledo, Columbia, OH, USA) with precision to $0.1 \mathrm{mg}$. Due to low individual larval weights, larvae were weighed in batches of 5 and the batch weight was divided by 5 to obtain individual weights $(n=200$, 40 I. pacificus batches; $n=230,46$ I. scapularis batches). Unengorged larval I. scapularis and I. pacificus from the same BEI stock as those used in the experiments were also measured to determine the weights for each species prior to feeding.

\section{Molting success}

Successfully fed larval I. scapularis and I. pacificus were maintained in plastic vials at a humidity of $98 \%$ [42] and a 16:8 h light:dark photoperiod until individuals either molted to the nymphal life stage or died. Engorged larvae took approximately 2 months to molt during which time freshly molted ticks were moved to clean vials. Those that had not molted after 2 months and were immobile appeared to be covered in tick waste (tick feces, exuviae), which is common in the high humidity environment, and were presumed dead [45].

\section{Pathogen acquisition (host to tick)}

Pathogen acquisition efficiency was measured in larval I. pacificus and I. scapularis through feeding ticks on infected $\mathrm{C} 3 \mathrm{H} / \mathrm{HeN}$ laboratory mice. To account for the potentially confounding effects of differences in regional B. burgdorferi strains, we conducted infection trials with mice infected with either CA4, a strain originally isolated from California [46], or B31, a strain from the Northeast [47] in a $2 \times 2$ factorial design. Both strains had been passaged 4-6 times in the laboratory before use. Mice were needle-inoculated with $10^{5}$ spirochetes/mouse [48] using live culture grown in BSK-II. To confirm mouse infection status, one $2 \mathrm{~mm}$ ear tissue biopsy was taken from each mouse, extracted for DNA using a Qiagen DNeasy extraction kit (Qiagen, Valencia, CA, USA), and tested for infection through a nested PCR targeting the 5S-23S intergenic spacer region of Borrelia [49]. Positive PCR results were typically obtained by 3-4 weeks post-inoculation. As described in the above section, I. scapularis and I. pacificus were fed on mice infected with CA4 or B31 and collected from drop-off containers. All ticks were then stored in $70 \%$ ethanol at $-80{ }^{\circ} \mathrm{C}$ and, within two weeks, individually extracted and tested for infection via the PCR described above.

\section{Pathogen transmission (tick to host)}

Pathogen transmission efficiency from ticks to a bloodmeal host was measured in nymphal $I$. scapularis and I. pacificus through feeding on naïve $\mathrm{C} 3 \mathrm{H} / \mathrm{HeN}$ mice in the laboratory. Transmission to more ecologically relevant host species, such as Peromyscus spp., could not be achieved due to exceedingly low attachment rates of I. pacificus nymphs to Peromyscus under laboratory conditions (Chindy Peavey, personal communication). Putatively infected ticks used for this experiment were obtained through larval feeding on the B31 or CA4infected mice used in the pathogen acquisition experiment, and maintenance at $98 \%$ humidity in plastic vials in the laboratory until successful molting. Due to variable survival rates and numbers of successfully molted nymphs, we were unable to attach equal numbers of nymphs to mice (Additional file 1: Table S1). Nymphs were then fed to repletion on uninfected $\mathrm{C} 3 \mathrm{H} / \mathrm{HeN}$ mice. Mice were tested for infection as described above. Because it is impossible to know the infection status of ticks prior to host attachment, we confirmed tick infection status after host feeding by nested PCR. Only mice fed with at least 1 post-hoc, PCR-confirmed, infected tick were included in the final tick-to-host transmission analysis.

\section{Results}

Host attachment success and feeding time

Of the 300 larvae of each tick species placed on P. maniculatus, $102 \mathrm{I}$. pacificus and $20 \mathrm{I}$. scapularis successfully attached and fed (Fig. 2). While I. pacificus had higher host attachment success, I. scapularis fed to repletion significantly faster ( $3.15 \pm 0.37$ days) than I. pacificus $(3.73 \pm 0.82$ days $)\left(t_{(63)}=4.98, P<0.01\right)$.

\section{Engorgement weight}

Engorged I. pacificus larvae weighed significantly more $(0.412 \pm 0.185 \mathrm{mg})$ than engorged $I$. scapularis larvae $(0.265 \pm 0.007 \mathrm{mg})\left(t_{(29)}=5.47, P<0.001\right)$ (Fig. 3, Additional file 2: Table S2) after feeding on P. maniculatus. Prior to feeding, there was no difference in the weights of larval I. pacificus $(0.028 \pm 0.001 \mathrm{mg})$ and I. scapularis $(0.033 \pm 0.0002 \mathrm{mg})\left(t_{(47)}=-0.90, P=0.37\right)$ (Fig. 3).

\section{Molting success}

Of the engorged ticks maintained for possible molting, an equal proportion of $I$. pacificus $(60 / 100,60 \%)$ and $I$. scapularis $(11 / 18,61.1 \%)$ successfully molted to the next life stage $\left(\chi^{2}=0.001, d f=1, P=1\right)$ (Table 1$)$. These counts were taken 2 months after drop-off when all ticks had either died or molted. 


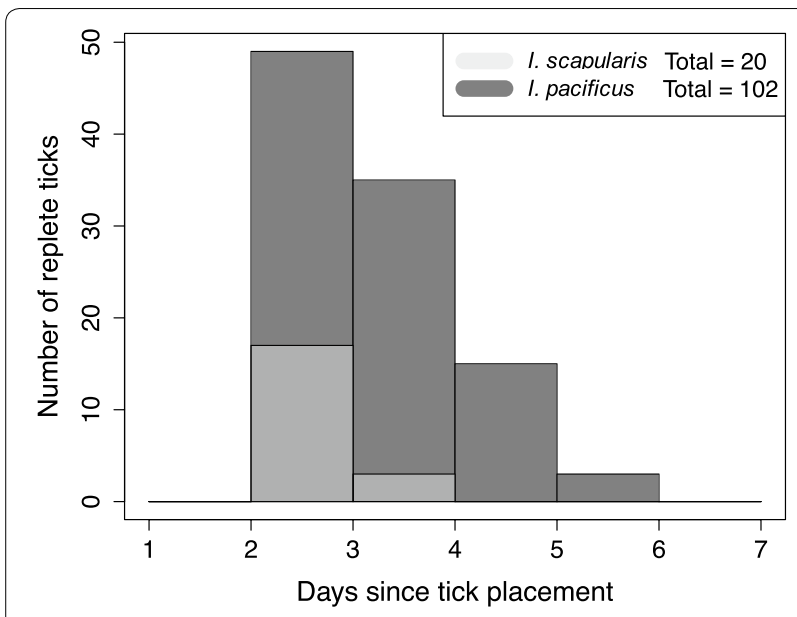

Fig. 2 Host attachment and feeding rates of larval I. scapularis and 1. pacificus. Bar heights indicate the number of ticks, out of 300 for each species, that fed to repletion on the subsequent 7 days after placement on P. maniculatus. Similarly, "Total" refers to the total number of larvae that successfully completed feeding

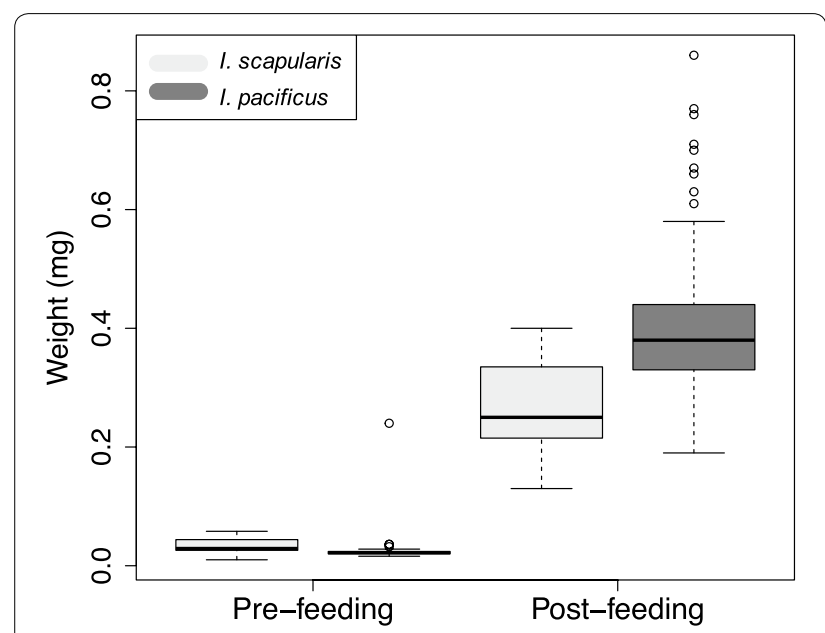

Fig. 3 Larval I. scapularis and I. pacificus weights pre- and post-feeding to repletion on $P$. maniculatus. Horizontal bar and star denote statistically different weights $(P<0.01)$

\section{Pathogen acquisition (host to tick)}

We measured the infection status of 30 engorged larval ticks from each of the treatment groups (I. pacificus or $I$. scapularis fed on a B31 or CA4-infected mouse) to calculate pathogen acquisition percentages. We found $73 \%$ $(22 / 30)$ of $I$. scapularis that fed on mice infected with B31, the northeastern pathogen strain, acquired infection, while only $20 \%$ (6/30) of I. scapularis acquired infection from mice infected with CA4, the western pathogen strain (Fig. 4). Similarly, 73\% (22/30) of I. pacificus fed on CA4-infected mice acquired the pathogen, compared to $20 \%(6 / 30)$ of those fed on B31-infected mice (Fig. 4).
Thus, pathogen acquisition was identical for each vector exposed to its sympatric pathogen strain, and identical but lower for allopatric pathogen strains.

\section{Pathogen transmission (tick to host)}

We measured the infection status of mice 10 days after feeding by infected ticks from each treatment group to calculate pathogen transmission percentages. Pathogen transmission was higher from I. scapularis than I. pacificus for both pathogen strains $\left(\chi^{2}=8.55, d f=1, P=0.003\right)$ (Table 2). For I. scapularis nymphs infected with B31 or CA4, transmission to naïve mice occurred in $100 \%(5 / 5)$ or $83 \%(5 / 6)$ of mice, respectively. For I. pacificus, no mice became infected from either B31- or CA4-infected nymphs (0/2 mice and $0 / 3$ mice, respectively). However, unequal numbers of infected I. scapularis and I. pacificus nymphs were applied to each mouse due to experimental difficulties and sample limitations of infected nymphs (see Table 2), which may confound conclusions about the transmission efficiency of individual ticks of each species.

\section{Discussion}

Efficient vector-borne pathogen transmission cycles require competent vectors-arthropod species that can reliably acquire, maintain, and transmit pathogens [12, 29]. We decomposed vector competence into measurable vector traits: host attachment and feeding success; larval molting success; pathogen acquisition (host to tick); and pathogen transmission (tick to host). We compared performance of these traits between the two USA Lyme disease vectors, I. scapularis and I. pacificus, to investigate if

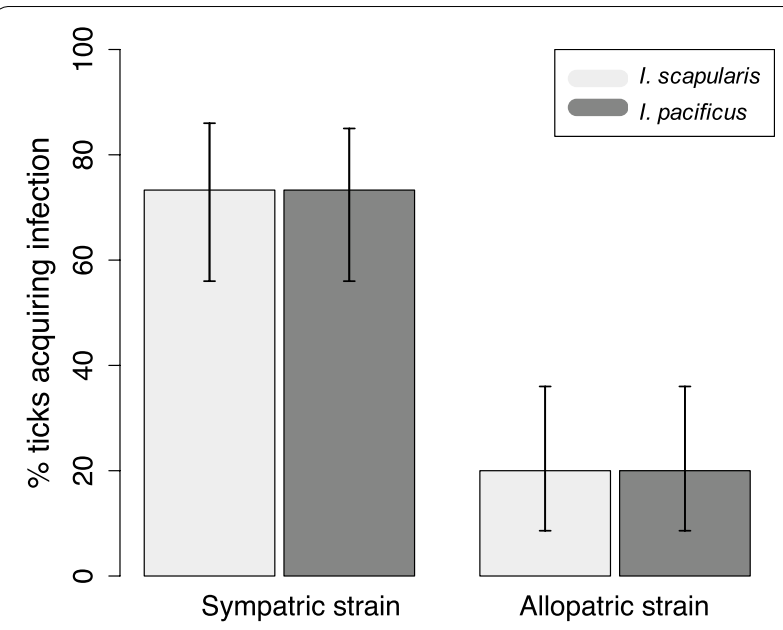

Fig. 4 Percent of larval I. scapularis and I. pacificus acquiring $B$. burgdorferi from an infectious mouse blood meal. Mice were infected with B. burgdorferi strain B31 or CA4, the pathogen strains sympatric for I. scapularis or I. pacificus, respectively. Errors bars denote 95\% credible intervals 
Table 2 Pathogen transmission rates from I. scapularis and I. pacificus to naïve $\mathrm{C} 3 \mathrm{H} / \mathrm{HeN}$ mice

\begin{tabular}{|c|c|c|c|c|}
\hline Mouse ID & Tick species & Pathogen strain & $\begin{array}{l}\text { No. of } \\
\text { feeding } \\
\text { ticks }^{\mathrm{a}}\end{array}$ & $\begin{array}{l}\text { Mouse infection } \\
\text { status }\end{array}$ \\
\hline 1 & I. scapularis & B31 & $7 / 10$ & Infected \\
\hline 2 & I. scapularis & B31 & $9 / 11$ & Infected \\
\hline 3 & I. scapularis & B31 & $6 / 7$ & Infected \\
\hline 4 & I. scapularis & B31 & $8 / 9$ & Infected \\
\hline 5 & I. scapularis & B31 & $5 / 5$ & Infected \\
\hline 6 & I. scapularis & CA4 & $3 / 6$ & Infected \\
\hline 7 & I. scapularis & CA4 & $4 / 5$ & Infected \\
\hline 8 & I. scapularis & CA4 & $2 / 6$ & Infected \\
\hline 9 & I. scapularis & CA4 & $1 / 8$ & Infected \\
\hline 10 & I. scapularis & CA4 & $5 / 5$ & Infected \\
\hline 11 & I. scapularis & CA4 & $2 / 6$ & Not infected \\
\hline 12 & 1. pacificus & B31 & $0 / 3$ & Not infected \\
\hline 13 & I. pacificus & B31 & $0 / 4$ & Not infected \\
\hline 14 & I. pacificus & B31 & $0 / 3$ & Not infected \\
\hline 15 & I. pacificus & B31 & $0 / 3$ & Not infected \\
\hline 16 & I. pacificus & B31 & $1 / 1$ & Not infected \\
\hline 17 & I. pacificus & B31 & $1 / 1$ & Not infected \\
\hline 18 & I. pacificus & CA4 & $2 / 2$ & Not infected \\
\hline 19 & I. pacificus & CA4 & $2 / 2$ & Not infected \\
\hline 20 & I. pacificus & CA4 & $5 / 5$ & Not infected \\
\hline
\end{tabular}

Note: Rows in bold indicate ticks fed on these mice were infected, while nonbold rows indicate ticks were uninfected

${ }^{a}$ Number infected/total number

variation in vector competence may contribute to broad geographical differences in Lyme disease incidence. Despite high genetic similarity between these two species, we detected significant differences in host feeding and pathogen transmission abilities, but no difference in larval molting success or pathogen acquisition rates (Table 1).

The choice and success of larval host feeding is a critical factor in Lyme disease transmission efficiency [22] as it presents the first opportunity for pathogen acquisition, and dictates the infection status of the nymphal stage, responsible for the majority of human Lyme disease cases $[50,51]$. Natural host usage by $I$. scapularis and I. pacificus is known to be markedly different, with immature I. scapularis feeding more commonly on small mammals such as the white-footed mouse, Peromyscus leucopus [52, 53], and immature $I$. pacificus feeding predominantly on the western fence lizard, Sceloporus occidentalis [27, 43]. As small mammal hosts are generally more highly competent for $B$. burgdorferi [53-55], the rate of vectors attaching and successfully feeding on these hosts is an important factor in the Lyme disease transmission cycle [56]. In our experimental manipulation, we detected a five-fold greater abundance of I. pacificus attaching to and successfully feeding on a common small mammal host, Peromyscus maniculatus, compared to I. scapularis (Fig. 2). This finding supports previous observations that $I$. pacificus readily parasitize rodents when available [22, 43], despite more frequently parasitizing lizards in the field. These findings suggest that B. burgdorferi transmission in the western USA is not limited by $I$. pacificus host feeding abilities. Further, host community shifts favoring small mammals, or I. pacificus population expansions to areas with greater small mammal abundances relative to lizards, present opportunities for more efficient $B$. burgdorferi transmission cycles than currently observed. The relatively low attachment rates of $I$. scapularis on P. maniculatus observed here may not reflect $I$. scapularis attachment to all rodents, as $I$. scapularis more commonly parasitizes $P$. leucopus in the field $[52,53]$ rather than P. maniculatus used here. However prior laboratory experiments have demonstrated that $I$. scapularis attaches at least as readily to P. maniculatus as to P. leucopus [57].

In addition to higher host parasitism rates, we found I. pacificus larvae remained attached to hosts for longer (Fig. 2) and obtained higher engorgement weights than I. scapularis (Fig. 3). Although not directly measured here, attachment duration and tick engorgement can reflect host immune resistance to tick infestation [5860]. Namely, tick feeding is known to induce a complex array of host immune responses [59, 61, 62]. These host immune responses can result in immunological resistance to tick infestation which can also confer host protection to tick-borne pathogens [63-66]. Development of this host immunological resistance has been associated with shorter host attachment times [64, 67, 68], decreased tick engorgement [58, 64, 67, 69, 70], and decreased tick parasitism rates $[69,71]$, but see $[57$, $72,73]$. Thus, the results obtained here may indicate enhanced host resistance to pathogens transmitted by $I$. scapularis than those from I. pacificus. Further, increased tick engorgement has been associated with greater tick molting success [74], fecundity [75], and larger molted body sizes or weights which may enhance survival [70, 74, 75]. However, engorged larval $I$. scapularis and $I$. pacificus molted at equally high rates in this study, and downstream effects on survival and fecundity were not measured here. Thus, the lower attachment duration and engorgement of I. scapularis relative to I. pacificus had no measured impact on vector survival, but could negatively impact tick fitness and pathogen transmission to hosts.

In contrast, results from the pathogen transmission experiment indicate that B. burgdorferi transmission was much higher from I. scapularis than I. pacificus 
(Table 2). Infected nymphal I. pacificus did not transmit either pathogen strain (B31 or CA4) to naïve laboratory mice, while I. scapularis transmitted B31 and CA4 to nearly all mice. As pathogen transmission from nymphal to vertebrate hosts is a key determinant of Lyme disease maintenance and human disease risk [17, 76, 77], the low transmission rates from I. pacificus represent a potential bottleneck in pathogen dynamics in the western USA. However, transmission to $\mathrm{C} 3 \mathrm{H} / \mathrm{HeN}$ laboratory mice used in this experiment may not reflect transmission dynamics to Peromyscus or other small mammal species naturally encountered by I. scapularis and I. pacificus. Specifically, pathogen reservoir hosts for I. pacificus transmission cycles include species such as western gray squirrels and dusky-footed woodrats [78]; transmission to these hosts was not measured in the present study but may be higher given the higher infection prevalence measured for these species relative to $P$. maniculatus [42]. Further, as we could not test the infection status of each tick prior to loading on a host, the number of infected ticks applied to each $\mathrm{C} 3 \mathrm{H} / \mathrm{HeN}$ mouse, when measured after feeding, were incidentally higher for I. scapularis than I. pacificus and varied between mouse replicates (Table 2). Thus, variation in infected tick abundance and lack of shared history between host and vector species may confound the results obtained here or limit their ecological relevance. However, the $\mathrm{C} 3 \mathrm{H} / \mathrm{HeN}$ mouse model is routinely used in B. burgdorferi transmission studies as this species is highly capable of acquiring infection [79-82] and does not develop resistance to I. pacifcus infestation in laboratory trials [83]. Further, heavier tick infestations can generate stronger host immune responses [84], thus the effect of loading more I. scapularis on mice relative to I. pacificus, does not necessarily favor higher transmission from I. scapularis. Overall, while the experimental conditions do not exactly mirror those of natural environments, the highly contrasting transmission efficiencies of I. scapularis and I. pacificus observed here highlight vector-to-host transmission as a vector trait potentially driving differences in transmission efficiency between the eastern and western USA.

These same differences between I. scapularis and $I$. pacificus were not observed when comparing pathogen acquisition abilities. An identical proportion of I. scapularis and I. pacificus acquired their sympatric pathogen strain (B31 and CA4, respectively) when fed on infected mice. Pathogen acquisition efficiency was also identical between I. scapularis and I. pacificus for their respective allopatric strain, although lower than that of their sympatric strain. These results indicate that $I$. scapularis and I. pacificus are equally capable of acquiring pathogens from infected hosts, and highlight the importance of coevolutionary history between vectors and pathogen strain in vector competence.

Given their overlapping life history strategies, vectors and pathogens form intimate relationships [85]. These tight relationships can evolve into positive [86-92] or negative [93-98] associations, with outcomes often varying based on the degree and duration of evolutionary association [89]. In laboratory experiments, B. burgdorferi infection has been shown to promote nymphal survival and host-seeking under suboptimal environmental conditions [99, 100], suggesting a co-evolved mutualistic relationship. Our finding that sympatric vector species and B. burgdorferi strains exhibit more efficient pathogen dynamics than allopatric pairings further supports this notion. However, recent genomic work found no support for coevolution between B. burgdorferi and its tick vector [101]. The results found in this study may thus reflect nascent mutualistic associations arising between $B$. burgdorferi and ixodid vectors not yet reflected in their phylogenetic structure. However, we did not directly measure the effect of pathogen infection on tick behavior, survivorship, or reproductive fitness. Given the species-specific differences we document in this study, future studies should evaluate the pathogenic impact of $B$. burgdorferi infection on tick fitness. Further investigation of coevolution between ixodid vectors and B. burgdorferi strains are needed to better understand the role of coevolution in current transmission dynamics.

While our common-garden laboratory experiments revealed significant differences in pathogen dynamics and host attachment rates between I. scapularis and I. pacificus, these results may not reflect natural differences in these tick species in all regions and populations. In particular, as our I. scapularis and I. pacificus populations were sourced from Rhode Island and California, respectively, these results may not extend to southern populations of either species, as these are known to be genetically and ecologically distinct $[102,103]$. However, northeastern and midwestern I. scapularis populations lack significant genetic structuring, as do northern $I$. pacificus populations [102, 103], suggesting the tick species-specific differences detected in our study are likely applicable to tick populations in areas with higher Lyme disease incidence. Further, Lyme disease transmission to humans is rare in the southeastern and southwestern USA, as vector populations here are less likely to quest above the leaf litter due to warmer and drier climate conditions and genetic differences in these populations [20, 104-109]. Thus, our results indicating vector-specific differences also contribute to variation in Lyme disease transmission efficiency may be most relevant in regions that are otherwise climatically and ecologically suitable for disease transmission. 


\section{Conclusions}

Despite high genetic similarity between the two USA Lyme disease vectors, we found significant variation in $I$. scapularis and I. pacificus performance in traits related to vector competence. Ixodes pacificus displayed greater host feeding abilities, but far lower pathogen transmission rates relative to $I$. scapularis. Inefficient tick to host transmission may present a barrier to B. burgdorferi transmission cycles in the western USA, contributing to broad regional differences in Lyme disease incidence. Host to tick transmission rates were identical between tick species, but lower for allopatric tick species and pathogen strains than sympatric pairings. These findings highlight the importance of vector-pathogen coevolutionary history, as well as vector traits, in determining Lyme disease transmission efficiency.

\section{Supplementary information}

Supplementary information accompanies this paper at https://doi. org/10.1186/s13071-020-3893-x.

Additional file 1: Table S1. Host attachment rates for larval I. pacificus and I. scapularis fed on naïve Peromyscus maniculatus. 150 larvae (either I. pacificus or I. scapularis) were placed on each of four mice.

Additional file 2: Table S2. Weights of unengorged and engorged larval I. pacificus and I. scapularis (mg).

\section{Abbreviations}

PCR: polymerase chain reaction; DNA: deoxyribonucleic acid; BSK-II: Barbour-Stoenner-Kelley.

\section{Acknowledgements}

We would like to thank Steven Sun and Adrienne Almarinez from San Francisco State University for laboratory assistance, and Mona Luo for the graphics used in the Graphical Abstract and Fig. 1 (http://www.monaluo.com). The following reagent was provided by Centers for Disease Control and Prevention for distribution by BEI Resources, NIAID, NIH: Ixodes scapularis Nymph (Live), NR-44116.

\section{Authors' contributions}

LIC, XFY and AS designed the project. LIC and YY performed the laboratory experiments. AS and XFY provided new reagents and analytical tools. LIC analyzed the data. LIC and AS wrote the manuscript. All authors read and approved the final manuscript.

\section{Funding}

This work was supported by NSF Awards 175037, 1745411, 1427772 to AS and by NIH Award R01 Al083640 to XFY.

\section{Availability of data and materials}

All data generated or analyzed during this study are included in this published article and its additional files.

\section{Ethics approval and consent to participate}

All procedures with animals were approved by San Francisco State University (IACUC Protocol No. AU15-051b) and by Indiana University (IACUC Protocol No. 11339).

\section{Consent for publication}

Not applicable.

\section{Competing interests}

The authors declare that they have no competing interests.

\section{Author details}

${ }^{1}$ Department of Biology, Stanford University, Stanford, CA, USA. ${ }^{2}$ Department of Microbiology and Immunology, Indiana University School of Medicine, Indianapolis, IN, USA. ${ }^{3}$ Department of Biology, San Francisco State University, San Francisco, CA, USA.

Received: 24 July 2019 Accepted: 7 January 2020

Published online: 14 January 2020

\section{References}

1. Eisen RJ, Kugeler KJ, Eisen L, Beard CB, Paddock CD. Tick-borne zoonoses in the United States: persistent and emerging threats to human health. ILAR J. 2017:58:319-35.

2. Rainey T, Occi JL, Robbins RG, Egizi A. Discovery of Haemaphysalis longicornis (Ixodida:Ixodidae) parasitizing a sheep in New Jersey, United States. J Med Entomol. 2018;55:757-9.

3. Wormser GP, Dattwyler RJ, Shapiro ED, Halperin JJ, Steere AC, Klempner MS, et al. The clinical assessment, treatment, and prevention of Lyme disease, human granulocytic anaplasmosis, and babesiosis: clinical practice guidelines by the infectious diseases society of America. Clin Infect Dis. 2006:43:1089-134.

4. Sonenshine DE. Range expansion of tick disease vectors in North America: implications for spread of tick-borne disease. Int J Environ Res Public Health. 2018:15:478.

5. Robinson SJ, Neitzel DF, Moen RA, Craft ME, Hamilton KE, Johnson LB, et al. Disease risk in a dynamic environment: the spread of tick-borne pathogens in Minnesota, USA. EcoHealth. 2015;12:152-63.

6. Ogden $\mathrm{NH}$, Lindsay LR, Leighton PA. Predicting the rate of invasion of the agent of Lyme disease Borrelia burgdorferi. J Appl Ecol. 2013:50:510-8.

7. Leighton PA, Koffi JK, Pelcat Y, Lindsay LR, Ogden NH. Predicting the speed of tick invasion: an empirical model of range expansion for the Lyme disease vector Ixodes scapularis in Canada. J Appl Ecol. 2012;49:457-64.

8. Estrada-Peña A, de la Fuente J. The ecology of ticks and epidemiology of tick-borne viral diseases. Antivir Res. 2014;108:104-28.

9. Bacon RM, Kugeler KJ, Mead PS. Surveillance for Lyme disease-United States, 1992-2006. MMWR Surveill Summ. 2008;57:1-9.

10. Eisen RJ, Eisen L, Beard CB. County-scale distribution of Ixodes scapularis and Ixodes pacificus (Acari:Ixodidae) in the continental United States. J Med Entomol. 2016:53:349-86.

11. Lane RS, Piesman J, Burgdorfer W. Lyme borreliosis: relation of its causative agent to its vectors and hosts in North America and Europe. Annu Rev Entomol. 1991;36:587-609.

12. Sonenshine DE, Mather TN. Ecological dynamics of tick-borne zoonoses. New York: Oxford University Press; 1994.

13. Kilpatrick AM, Dobson ADM, Levi T, Salkeld DJ, Swei A, Ginsberg HS, et al. Lyme disease ecology in a changing world: consensus, uncertainty and critical gaps for improving control. Philos Trans R Soc B Biol Sci. 2017:372:20160117.

14. Brown R, Lane R. Lyme disease in California: a novel enzootic transmission cycle of Borrelia burgdorferi. Science. 1992;256:1439-42.

15. Schwartz AM, Hinckley AF, Mead PS, Hook SA, Kugeler KJ. Surveillance for Lyme disease-United States, 2008-2015. MMWR Surveill Summ. 2017:66:1-12.

16. Keesing F, Brunner J, Duerr S, Killilea M, LoGiudice K, Schmidt K, et al. Hosts as ecological traps for the vector of Lyme disease. Proc R Soc B Biol Sci. 2009;276:3911-9.

17. LoGiudice K, Ostfeld RS, Schmidt KA, Keesing F. The ecology of infectious disease: effects of host diversity and community composition on Lyme disease risk. Proc Natl Acad Sci USA. 2003;100:567-71.

18. Kurtenbach K, Hanincová K, Tsao Jl, Margos G, Fish D, Ogden NH. Fundamental processes in the evolutionary ecology of Lyme borreliosis. Nat Rev Microbiol. 2006;4:660-9. 
19. Randolph SE, Green RM, Peacey MF, Rogers DJ. Seasonal synchrony: the key to tick-borne encephalitis foci identified by satellite data. Parasitology. 2000;121:15-23.

20. Lane RS, Fedorova N, Kleinjan JE, Maxwell M. Eco-epidemiological factors contributing to the low risk of human exposure to ixodid tick-borne borreliae in southern California, USA. Ticks Tick Borne Dis. 2013:4:377-85.

21. Arsnoe IM, Hickling GJ, Ginsberg HS, McElreath R, Tsao Jl. Different populations of blacklegged tick nymphs exhibit differences in questing behavior that have implications for human Lyme disease risk. PLoS ONE. 2015;10:e0127450.

22. James AM, Oliver JH. Feeding and host preference of immature Ixodes dammini, I. scapularis, and I. pacificus (Acari:Ixodidae). J Med Entomol. 1990:27:324-30.

23. McLain DK, Wesson DM, Collins FH, Oliver JH Jr. Evolution of the rDNA spacer, ITS 2, in the ticks Ixodes scapularis and I. pacificus (Acari:Ixodidae). Heredity. 1995;75:303-19.

24. Eisen RJ, Eisen L, Ogden NH, Beard CB. Linkages of weather and climate with Ixodes scapularis and Ixodes pacificus (Acari:Ixodidae), enzootic transmission of Borrelia burgdorferi, and Lyme disease in North America. J Med Entomol. 2016;53:250-61.

25. Apperson CS, Levine JF, Evans TL, Braswell A, Heller J. Relative utilization of reptiles and rodents as hosts by immature Ixodes scapularis (Acari:lxodidae) in the coastal plain of North Carolina, USA. Exp Appl Acarol. 1993;17:719-31.

26. Ostfeld RS, Keesing F. Biodiversity and disease risk: the case of Lyme disease. Conserv Biol. 2000;14:722-8.

27. Eisen L, Eisen RJ, Lane RS. The roles of birds, lizards, and rodents as hosts for the western black-legged tick Ixodes pacificus. J Vector Ecol. 2004;29:295-308.

28. Hahn MB, Jarnevich CS, Monaghan AJ, Eisen RJ. Modeling the geographic distribution of Ixodes scapularis and Ixodes pacificus (Acari:Ixodidae) in the contiguous United States. J Med Entomol. 2016;53:1176-91.

29. Hardy JL, Houk EJ, Kramer LD, Reeves WC. Intrinsic factors affecting vector competence of mosquitoes for arboviruses. Annu Rev Entomol. 1983;28:229-62

30. de la Fuente J, Antunes S, Bonnet S, Cabezas-Cruz A, Domingos AG, Estrada-Peña A, et al. Tick-pathogen interactions and vector competence: identification of molecular drivers for tick-borne diseases. Front Cell Infect Microbiol. 2017;7:114.

31. Estrada-Peña A. Ticks as vectors: taxonomy, biology and ecology. Rev Sci Tech. 2015;34:53-65.

32. Dolan MC, Piesman J, Mbow ML, Maupin GO, PéTer O, Brossard $M$, et al. Vector competence of Ixodes scapularis and Ixodes ricinus (Acari:Ixodidae) for three genospecies of Borrelia burgdorferi. J Med Entomol. 1998;35:465-70

33. Turell MJ, O'Guinn ML, Dohm DJ, Jones JW. Vector competence of North American mosquitoes (Diptera:Culicidae) for West Nile virus. J Med Entomol. 2001;38:130-4.

34. Dolan MC, Maupin GO, Panella NA, Golde WT, Piesman J. Vector competence of Ixodes scapularis, I spinipalpis, and Dermacentor andersoni (Acari:Ixodidae) in transmitting Borrelia burgdorferi, the etiologic agent of Lyme disease. J Med Entomol. 1997;34:128-35.

35. Mather TN, Mather ME. Intrinsic competence of three Ixodid ticks (Acari) as vectors of the Lyme disease spirochete. J Med Entomol. 1990:27:646-50.

36. Steele GM, Nuttall PA. Difference in vector competence of two species of sympatric ticks, Amblyomma variegatum and Rhipicephalus appendiculatus, for Dugbe virus (Nairovirus, Bunyaviridae). Virus Res. 1989;14:73-84.

37. Plowright RK, Parrish CR, McCallum H, Hudson PJ, Ko Al, Graham AL, et al. Pathways to zoonotic spillover. Nat Rev Microbiol. 2017;15:502-10.

38. Troughton DR, Levin ML. Life cycles of seven ixodid tick species (Acari:Ixodidae) under standardized laboratory conditions. J Med Entomol. 2007:44:732-40.

39. Levin ML, Schumacher LBM. Manual for maintenance of multi-host ixodid ticks in the laboratory. Exp Appl Acarol. 2016;70:343-67.

40. Jones JK, Hall ER. The mammals of North America. 2nd ed. New York: Wiley; 1981
41. Bouchard C, Beauchamp G, Nguon S, Trudel L, Milord F, Lindsay LR, et al. Associations between /xodes scapularis ticks and small mammal hosts in a newly endemic zone in southeastern Canada: implications for Borrelia burgdorferi transmission. Ticks Tick Borne Dis. 2011;2:183-90.

42. Swei A, Briggs CJ, Lane RS, Ostfeld RS. Impacts of an introduced forest pathogen on the risk of Lyme disease in California. Vector Borne Zoonotic Dis. 2012;12:623-32.

43. Larson SR, Lee X, Paskewitz SM. Prevalence of tick-borne pathogens in two species of Peromyscus mice common in northern Wisconsin. J Med Entomol. 2018;55:1002-10.

44. Larson RT, Lee X, Zembsch T, Bron GM, Paskewitz SM. Immature Ixodes scapularis (Acari:Ixodidae) collected from Peromyscus leucopus (Rodentia:Cricetidae) and Peromyscus maniculatus (Rodentia:Cricetidae) nests in northern Wisconsin. J Med Entomol. 2020;57:304-7.

45. Lane RS, Brown RN, Piesman J, Peavey CA. Vector competence of Ixodes pacificus and Dermacentor occidentalis (Acari:Ixodidae) for various isolates of Lyme disease spirochetes. J Med Entomol. 1994;31:417-24.

46. Peavey CA, Lane RS. Field and laboratory studies on the timing of oviposition and hatching of the western black-legged tick, Ixodes pacificus (Acari:Ixodidae). Exp Appl Acarol. 1996;20:695-711.

47. SlowikTJ, Lane RS. Feeding preferences of the immature stages of three western North American Ixodid ticks (Acari) for avian, reptilian, or rodent hosts. J Med Entomol. 2009;46:115-22.

48. Schwan TG, Schrumpf ME, Karstens RH, Clover JR, Wong J, Daugherty M, et al. Distribution and molecular analysis of Lyme disease spirochetes, Borrelia burgdorferi, isolated from ticks throughout California. J Clin Microbiol. 1993;31:13

49. Burgdorfer W, Barbour AG, Hayes S, Benach J, Grunwaldt E, Davis J. Lyme disease-a tick-borne spirochetosis? Science. 1982;216:1317-9.

50. He M, Ouyang Z, Troxell B, Xu H, Moh A, Piesman J, et al. Cyclic di-GMP is essential for the survival of the Lyme disease spirochete in ticks. PLoS Pathog. 2011;7:e1002133.

51. Postic D, Assous MV, Grimont PAD, Baranton G. Diversity of Borrelia burgdorferi sensu lato evidenced by restriction fragment length polymorphism of njf (5S)-rrl (23s) intergenic spacer amplicons. Int J Syst Ecol Microbiol. 1994:44:743-52.

52. Mead PS. Epidemiology of Lyme disease. Infect Dis Clin N Am. 2015;29:187-210.

53. Spielman A, Wilson ML, Levine JF, Piesman J. Ecology of Ixodes damminiborne human babesiosis and Lyme disease. Annu Rev Entomol. 1985;30:439-60.

54. Levine JF, Wilson ML, Spielman A. Mice as reservoirs of the Lyme disease spirochete. Am J Trop Med Hyg. 1985;34:355-60.

55. Mather TN, Wilson ML, Moore SI, Ribeiro JMC, Spielman A. Comparing the relative potential of rodents as reservoir of the Lyme disease spirochete (Borrelia burgdorferi). Am J Epidemiol. 1989;130:143-50.

56. Donahue JG, Piesman J, Spielman A. Reservoir competence of white-footed mice for Lyme disease spirochetes. Am J Trop Med Hyg. 1987:36:92-6.

57. Brown RN, Lane RS. Reservoir competence of four chaparral-dwelling rodents for Borrelia burgdorferi in California. Am J Trop Med Hyg. 1996;54:84-91.

58. Kurtenbach K, Kampen H, Dizij A, Arndt S, Seitz HM, Schaible UE, et al. Infestation of rodents with larval Ixodes ricinus (Acari; Ixodidae) is an important factor in the transmission cycle of Borrelia burgdorferi s.l. in German woodlands. J Med Entomol. 1995;32:807-17.

59. Hazler KR, Ostfeld RS. Larval density and feeding success of Ixodes scapularis on two species of Peromyscus. J Parasitol. 1995;81:870-5.

60. Wikel SK. Immune responses to arthropods and their products. Annu Rev Entomol. 1982;27:21-48.

61. Wikel SK. Host immunity to ticks. Annu Rev Entomol. 1996;41:1-22.

62. Wikel SK. Immunological control of hematophagous arthropod vectors: utilization of novel antigens. Vet Parasitol. 1988;29:235-64.

63. Brossard M, Rutti B, Haug T. Immunological relationships between host and ixodid ticks. In: Toft CA, Aeschlimann A, Bolis L, editors. Parasitehost associations: coexistence or conflict?. New York: Oxford University Press; 1991. p. 177-200.

64. Willadsen P, Jongejan F. Immunology of the tick-host interaction and the control of ticks and tick-borne diseases. Parasitol Today. 1999;15:258-62. 
65. Bell JF, Stewart SJ, Wikel SK Resistance to tick-borne Francisella tularensis by tick-sensitized rabbits: allergic klendusity. Am J Trop Med Hyg 1979:28:876-80.

66. Nazario S, Das S, de Silva AM, Deponte K, Marcantonio N, Anderson JF, et al. Prevention of Borrelia burgdorferi transmission in guinea pigs by tick immunity. Am J Trop Med Hyg. 1998;58:780-5.

67. Wikel SK. Host resistance to tick-borne pathogens by virtue of resistance to tick infestation. Ann Trop Med Parasitol. 1980;74:103-4.

68. Zeidner N, Dreitz M, Belasco D, Fish D. Suppression of acute Ixodes scapularis-induced Borrelia burgdorferi infection using tumor necrosis factor-a, interleukin-2, and interferon- $\gamma$. J Infect Dis. 1996;173:187-95.

69. Alani AJ, Herbert IV. Effect of host resistance on the feeding and reproductive performance of Haemaphysalis punctata and Ixodes ricinus ticks. Res Vet Sci. 1987:42:238-43.

70. Kemp DH, Koudstaal D, Roberts JA, Kerr JD. Boophilus microplus: the effect of host resistance on larval attachments and growth. Parasitology. 1976;73:123-36.

71. Wikel SK, Allen JR. Acquired resistance to ticks. I. Passive transfer of resistance. Immunology. 1976;30:311-6.

72. Koch HG. Suitability of birds and mammals as hosts for immature stages of the lone star tick, Amblyomma americanum (Acari:Ixodidae). J Med Entomol. 1981;18:93-8.

73. Anderson K, Ezenwa VO, Jolles AE. Tick infestation patterns in free ranging African buffalo (Syncercus caffer): effects of host innate immunity and niche segregation among tick species. Int J Parasitol Parasites Wildl. 2013:2:1-9.

74. Levin M, Fish D. Density-dependent factors regulating feeding success of Ixodes scapularis larvae (Acari:lxodidae). J Parasitol. 1998;84:36-43.

75. Davidar P, Wilson M, Ribeiro JMC. Differential distribution of immature Ixodes dammini (Acari:lxodidae) on rodent hosts. J Parasitol. 1989;75:898-904.

76. Koch HG, Hair JA. The effect of host species on the engorgement, molting success, and molted eeight of the gulf coast tick, Amblyomma maculatum Koch (Acarina:Ixodidae). J Med Entomol. 1975;12:213-9.

77. Amin OM. Growth of the dog tick Dermacentor variabilis Say (Acarina:Ixodidae). II. The effect of starvation and host species on its growth and fecundity. J Med Entomol. 1969;6:321-6.

78. Ostfeld RS. The ecology of Lyme-disease risk: complex interaction between seemingly unconnected phenomena determine risk of exposure to this expanding disease. Am Sci. 1997;85:338-46.

79. Stanek G, Wormser GP, Gray J, Strle F. Lyme borreliosis. Lancet. 2012:379:461-73.

80. Lane RS, Mun J, Eisen RJ, Eisen L. Western gray squirrel (Rodentia:Sciuridae): a primary reservoir host of Borrelia burgdorferi in Californian oak woodlands? J Med Entomol. 2005;42:9.

81. Zeidner NS, Schneider BS, Nuncio MS, Gern L, Piesman J. Coinoculation of Borrelia spp. with tick salivary gland lysate enhances spirochete load in mice and is tick species-specific. J Parasitol. 2002;88:1276-8.

82. Probert WS, LeFebvre RB. Protection of $\mathrm{C} 3 \mathrm{H} / \mathrm{HeN}$ mice from challenge with Borrelia burgdorferi through active immunization with OspA, OspB, or OspC, but not with OspD or the 83-kilodalton antigen. Infect Immun. 1994;62:1920-6.

83. de Silva AM. Borrelia burgdorferi OspA is an arthropod-specific transmission-blocking Lyme disease vaccine. J Exp Med. 1996;183:271-5.

84. Horká H, Černá-Kýčková K, Skallová A, Kopecký J. Tick saliva affects both proliferation and distribution of Borrelia burgdorferi spirochetes in mouse organs and increases transmission of spirochetes to ticks. Int J Med Microbiol. 2009:299:373-80.

85. Schoeler GB, Manweiler SA, Wikel SK. Cytokine responses of $\mathrm{C} 3 \mathrm{H} / \mathrm{HeN}$ mice infested with Ixodes scapularis or Ixodes pacificus nymphs. Parasite Immunol. 2000;22:39-48.

86. Kashino SS, Resende J, Sacco AMS, Rocha C, Proença L, Carvalho WA et al. Boophilus microplus: the pattern of bovine immunoglobulin isotype responses to high and low tick infestations. Exp Parasitol. 2005;110:12-21.

87. de la Fuente J, Villar M, Cabezas-Cruz A, Estrada-Peña A, Ayllón N, Alberdi P. Tick-host-pathogen interactions: conflict and cooperation. PLoS Pathog. 2016;12:e1005488.

88. Beanland L, Hoy CW, Miller SA, Nault LR. Influence of aster yellows phytoplasma on the fitness of aster leafhopper (Homoptera:Cicadellidae). Ann Entomol Soc Am. 2000;93:271-6.
89. Neelakanta G, Sultana H, Fish D, Anderson JF, Fikrig E. Anaplasma phagocytophilum induces Ixodes scapularis ticks to express an antifreeze glycoprotein gene that enhances their survival in the cold. J Clin Invest. 2010;120:3179-90.

90. Busby AT, Ayllón N, Kocan KM, Blouin EF, De La Fuente G, Galindo RC, et al. Expression of heat shock proteins and subolesin affects stress responses, Anaplasma phagocytophilum infection and questing behaviour in the tick, Ixodes scapularis. Med Vet Entomol. 2012;26:92-102.

91. Pelz-Stelinski KS, Killiny N. Better together: association with "Candidatus Liberibacter asiaticus" increases the reproductive fitness of its insect vector, Diaphorina citri (Hemiptera:Liviidae). Ann Entomol Soc Am. 2016;109:371-6.

92. Randolph SE. The effect of Babesia microti on feeding and survival in its tick vector, Ixodes trianguliceps. Parasitology. 1991;102:9-16.

93. Belliure B, Janssen A, Maris PC, Peters D, Sabelis MW. Herbivore arthropods benefit from vectoring plant viruses. Ecol Lett. 2005;8:70-9.

94. Ebbert MA, Nault LR. Survival in Dalbulus leafhopper vectors improves after exposure to maize stunting pathogens. Entomol Exp Appl. 2003; 100:311-24

95. Niebylski ML, Peacock MG, Schwan TG. Lethal effect of Rickettsia rickettsii on its tick vector (Dermacentor andersoni). Appl Environ Microbiol. 1999;65:773-8.

96. Sawaf BME, Sattar SAE, Shehata MG, Lane RP, Morsy TA. Reduced longevity and fecundity in Leishmania-infected sand flies. Am J Trop Med Hyg. 1994;51:767-70.

97. Duke BOL. Studies on factors influencing the transmission of onchocerciasis: I. The survival rate of Simulium damnosum under laboratory conditions and the effect upon it of Onchocerca volvulus. Ann Trop Med Parasitol. 1962;56:130-5.

98. Faran ME, Turell MJ, Romoser WS, Routier RG, Gibbs PH, Cannon TL, et al. Reduced survival of adult Culex pipiens infected with Rift Valley fever virus. Am J Trop Med Hyg. 1987;37:403-9.

99. Hogg JC, Hurd H. Malaria-induced reduction of fecundity during the first gonotrophic cycle of Anopheles stephensi mosquitoes. Med Vet Entomol. 1995:9:176-80.

100. McGaw MM, Chandler LJ, Wasieloski LP, Blair CD, Beaty BJ. Effect of La Crosse virus infection on overwintering of Aedes triseriatus. Am J Trop Med Hyg. 1998;58:168-75.

101. Lefcort $H$, Durden LA. The effect of infection with Lyme disease spirochetes (Borrelia burgdorferi) on the phototaxis, activity, and questing height of the tick vector Ixodes scapularis. Parasitology. 1996:113:97-103.

102. Herrmann C, Gern L. Survival of Ixodes ricinus (Acari:Ixodidae) under challenging conditions of temperature and humidity is influenced by Borrelia burgdorferi sensu lato infection. J Med Entomol. 2010:47:1196-204.

103. Walter KS, Carpi G, Caccone A, Diuk-Wasser MA. Genomic insights into the ancient spread of Lyme disease across North America. Nat Ecol Evol. 2017:1:1569-76.

104. Humphrey PT, Caporale DA, Brisson D. Uncoordinated phylogeography of Borrelia burgdorferi and its tick vector, Ixodes scapularis. Evolution. 2010;64:2653-63.

105. Kain DE, Sperling FAH, Lane RS. Population genetic structure of Ixodes pacificus (Acari:Ixodidae) using allozymes. J Med Entomol. 1997:34:441-50.

106. MacDonald AJ, Hyon DW, Brewington JB, O'Connor KE, Swei A, Briggs CJ. Lyme disease risk in southern California: abiotic and environmental drivers of Ixodes pacificus (Acari:Ixodidae) density and infection prevalence with Borrelia burgdorferi. Parasit Vectors. 2017;10:7.

107. Arsnoe I, Tsao Jl, Hickling GJ. Nymphal Ixodes scapularis questing behavior explains geographic variation in Lyme borreliosis risk in the eastern United States. Ticks Tick Borne Dis. 2019;10:553-63.

108. Diuk-Wasser MA, Vourc'h G, Cislo P, Hoen AG, Melton F, Hamer SA, et al. Field and climate-based model for predicting the density of host-seeking nymphal Ixodes scapularis, an important vector of tickborne disease agents in the eastern United States. Glob Ecol Biogeogr. 2010;19:504-14

109. Ginsberg HS, Albert M, Acevedo L, Dyer MC, Arsnoe IM, Tsao Jl, et al. Environmental factors affecting survival of immature Ixodes scapularis and implications for geographical distribution of Lyme disease: the climate/behavior hypothesis. PLoS ONE. 2017;12:e0168723. 
110. Randolph SE. Tick ecology: processes and patterns behind the epidemiological risk posed by ixodid ticks as vectors. Parasitology. 2004;129:S37-65.

111. Wikel SK, Ramachandra RN, Bergman DK, Burkot TR, Piesman J. Infestation with pathogen-free nymphs of the tick Ixodes scapularis induces host resistance to transmission of Borrelia burgdorferi by ticks. Infect Immun. 1997:65:335-8.

112. Hodzic E, Fish D, Maretzki CM, Silva AMD, Feng S, Barthold SW. Acquisition and transmission of the agent of human granulocytic ehrlichiosis by Ixodes scapularis ticks. J Clin Microbiol. 1998;36:3574-8.

113. Katavolos P, Armstrong PM, Dawson JE, Telford SR. Duration of tick attachment required for transmission of granulocytic ehrlichiosis. J Infect Dis. 1998;177:1422-5.
114. Piesman J, Sinsky RJ. Ability of Ixodes scapularis, Dermacentor variabilis, and Amblyomma americanum (Acari:Ixodidae) to acquire, maintain, and transmit Lyme disease spirochetes (Borrelia burgdorferi). J Med Entomol. 1988;25:336-9.

115. Lane RS, Burgdorfer W. Transovarial and transstadial passage of Borrelia burgdorferi in the western black-legged tick, Ixodes pacificus (Acari:Ixodidae). Am J Trop Med Hyg. 1987;37:188-92.

\section{Publisher's Note}

Springer Nature remains neutral with regard to jurisdictional claims in published maps and institutional affiliations.
Ready to submit your research? Choose BMC and benefit from:

- fast, convenient online submission

- thorough peer review by experienced researchers in your field

- rapid publication on acceptance

- support for research data, including large and complex data types

- gold Open Access which fosters wider collaboration and increased citations

- maximum visibility for your research: over $100 \mathrm{M}$ website views per year

At BMC, research is always in progress.

Learn more biomedcentral.com/submissions 